\title{
Equivalências semântica e conceitual da versão em português do National College Health Assessment II
}

\author{
Semantic and conceptual equivalences of the \\ Portuguese version of the National College \\ Health Assessment II
}

\footnotetext{
1 Centro de Educação Física

e Esporte, Universidade

Estadual de Londrina,

Londrina, Brasil.

Correspondência

D. P. Guedes

Centro de Educação Física e

Esporte, Universidade Estadual

de Londrina.

Rua Ildefonso Werner 177,

Londrina, PR 86055-545,

Brasil.

darta@sercomtel.com.br
}

\begin{abstract}
The objective of this study was to describe the semantic and conceptual equivalences of the National College Health Assessment II (NCHA II). The original version of the NCHA II was translated into Portuguese and back-translated into English. A committee of experts analyzed the different versions of the questionnaire. The version of the translated NCHA II questionnaire was experimentally administered to a sample of 64 university students of both sexes. After minor changes identified in the translation process, the committee of experts concluded that the Portuguese version of the NCHA II showed semantic and conceptual equivalences. In conclusion, the initial stages of the process of cross-cultural adaptation of the NCHA II questionnaire were satisfactory. Future studies are necessary to identify psychometric properties and validation indicators prior to the effective recommendation of the instrument for safe use.
\end{abstract}

Health Behavior; Students; Questionnaires
Dartagnan Pinto Guedes 1

Márcio Teixeira 1

\section{Introdução}

Para muitos jovens, o ingresso no ensino universitário é marcado por período de maior autonomia, relativo distanciamento da família, novas amizades e experiências, enfrentando, desse modo, situações até então desconhecidas. Mas também se caracteriza por período de elevada vulnerabilidade na consolidação de hábitos saudáveis, em razão da dificuldade em lidar com transformações psicossociais e pressões impostas pela necessidade de adaptação às situações próprias do meio acadêmico.

Por se tratar de segmento relevante da população em geral, o American College Health Association (ACHA), desde a sua criação em 1920, tem procurado atender o segmento universitário norte-americano no que se refere às necessidades de saúde. Essa entidade exerce forte liderança no meio universitário daquele país e procura atender as faculdades e universidades filiadas quanto à monitoração de indicadores de saúde que possam afetar o desempenho acadêmico e a qualidade de vida no campus. Para subsidiar suas ações, o ACHA idealizou o questionário autoadministrado National College Health Assessment (NCHA) que, além de características demográficas, envolve questões relacionadas aos comportamentos de proteção e risco para a saúde, incluindo sete módulos: (a) informação em saúde, segurança pessoal e violência; (b) bebida alcoólica, tabaco e outras drogas; (c) atividade sexual e 
contracepção; (d) peso corporal, nutrição e exercício físico; (e) saúde mental; (f) saúde física; e (g) dificuldades para o desempenho acadêmico 1 .

A primeira versão do NCHA foi idealizada em 1998 por grupo de trabalho interdisciplinar de profissionais vínculados à área de saúde das faculdades e universidades filiadas ao ACHA. Seu delineamento resultou da compilação de vários instrumentos disponíveis na época, destacandose o National College Health Risk Behavior Survey, o Core Alcohol and Drug Survey e o Monitoring the Future Study. Após testagem inicial de campo e identificada a confiabilidade e a validade de sua primeira versão, o NCHA passou a ser sistematicamente utilizado em levantamentos de dados locais e nacional, oferecendo importantes informações aos serviços de assistência à saúde das instituições de ensino universitário, aos educadores de saúde e aos gestores universitários.

Mais recentemente, a versão original do NCHA foi revisada, sendo introduzidas importantes modificações, o que resultou no NCHA II. Embora as dimensões e o formato do questionário tenham permanecido os mesmos, na versão revisada uma quantidade significativa de questões foram modificadas e novas questões foram adicionadas na tentativa de ampliar o rol de comportamentos de proteção e risco, percepções e atitudes sobre temas de saúde. Especificamente, a versão revisada incluiu lista atualizada de drogas ilícitas, métodos contraceptivos e vacinas. Novos itens foram disponibilizados para levantar informações quanto ao comportamento de sono, à ocorrência de lesões intencionais, ao uso/ abuso de medicamentos e a sintomas de outros desfechos relacionados à saúde mental 2 .

No Brasil, não existem programas sistematizados de vigilância do conjunto de comportamentos de proteção e risco para a saúde da população universitária. Os estudos disponibilizados concentram seus resultados em comportamentos isolados, como uso de bebida alcoólica, tabaco e outras drogas, alimentação, prática de atividade física, práticas sexuais e contraceptivas e outras condutas de saúde ${ }^{3}$. Além disso, estudiosos da área têm dificuldade em identificar instrumentos no idioma português padronizados internacionalmente para realizar o levantamento das informações. Nesse caso, é necessário elaborar questionários específicos para cada estudo com base em adaptações de diferentes instrumentos, o que pode comprometer a qualidade das propriedades psicométricas e dificultar comparações entre estudos.

Portanto, diante da necessidade de reunir informações relacionadas aos comportamentos de proteção e risco para a saúde no âmbito universitário, mediante instrumentos apropriados à cultura dos jovens brasileiros, o objetivo do presente estudo foi avaliar as equivalências semântica e conceitual entre os itens do instrumento original e da versão em português do questionário NCHA II.

\section{Métodos}

Os protocolos de adaptação transcultural acompanharam procedimentos sugeridos por Guillemin et al. ${ }^{4}$. A tradução inicial do idioma original (inglês) para o português foi realizada de maneira independente por dois pesquisadores com entendimento detalhado do questionário NCHA II. Os dois pesquisadores tinham como idioma nativo o português e amplo domínio do idioma inglês, com experiência em traduções de textos acadêmicos. Além da tradução, foi solicitado que registrassem expressões que poderiam oferecer dúbia interpretação.

Um grupo bilíngue formado por três pesquisadores da área da saúde comparou os textos traduzidos, uniformizando o uso de expressões divergentes, e foi produzida uma versão única do questionário que sintetizou as duas versões anteriores. Em seguida, foi realizada a retrotradução do questionário por dois outros tradutores de maneira independente. Os tradutores escolhidos para essa etapa tinham como idioma nativo o inglês, domínio do idioma português e atuação como docente universitário em instituição brasileira. Solicitou-se aos tradutores que registrassem expressões que pudessem gerar dúvidas no processo de retrotradução. O grupo bilíngue comparou ambos os textos retrotraduzidos, produzindo versão única.

Um comitê analisou o processo de tradução e os resultados alcançados nas etapas anteriores. $\mathrm{O}$ comitê foi formado por nove membros, incluindo os autores do estudo, tradutores que participaram do processo de tradução/retrotradução e três docentes universitários da área de saúde, todos bilíngues - inglês-português. O comitê realizou revisão das sete versões do questionário NCHA II: versão original em língua inglesa, duas versões traduzidas para o idioma português, versão síntese de ambas as traduções para o idioma português, duas versões de retrotradução e versão síntese de ambas as retrotraduções.

O comitê realizou apreciação dos tipos de equivalências entre o questionário original e a versão no idioma português. Os membros receberam orientações por escrito sobre o objetivo do estudo e as definições adotadas para as equivalências. Cada um respondeu individualmente a um formulário de análise que comparava cada questão com a respectiva opção de resposta do 
questionário original, da versão síntese traduzida para o idioma português e da versão síntese de retrotradução, em relação às equivalências semântica e conceitual. O formulário de análise foi estruturado mediante escala diferencial com alternativas discretas: "inalterada", "pouco alterada”, "muito alterada” e "completamente alterada".

Próxima etapa do processo de adaptação transcultural foi a testagem do questionário traduzido, com intuito de verificar dificuldades e sugestões dos universitários quanto à compreensão das questões. O questionário foi aplicado experimentalmente em 64 estudantes universitários (35 moças e 29 rapazes), de diferentes cursos da área de saúde da Universidade Estadual de Londrina, Paraná (UEL). Os resultados foram considerados após nova apreciação pelos membros do comitê de análise bilíngue. $\mathrm{O}$ estudo foi aprovado pelo Comitê de Ética da UEL (parecer 172/10).

\section{Resultados}

Discretas divergências no uso de expressões foram observadas nas etapas do processo de tradução. As eventuais divergências foram discutidas no comitê de análise e prevaleceram as expressões de mais fácil compreensão e de uso frequente entre os estudantes universitários, para facilitar o entendimento. As dificuldades e sugestões apresentadas pelo grupo de estudantes universitários mediante a aplicação experimental do questionário traduzido, em número bastante reduzido, não apontaram necessidade de alterações.

Das 65 questões que compõem o NCHA II, uma delas foi excluída da versão traduzida para o português. A questão original que trata da possibilidade de o estudante universitário pertencer a uma fraternidade foi excluída, pelo fato de as universidades brasileiras não estarem organizadas envolvendo sociedades com tal característica. Dentre as 64 questões consideradas na versão traduzida do NCHA II, os membros do comitê de análise apontaram como "inalterada" as equivalências semântica e conceitual de 51 delas (80\%). Nas 13 restantes (20\%), os membros do comitê classificaram como "pouco alterada" ao menos uma das equivalências. A Tabela 1 apresenta a síntese dos ajustes realizados nessas questões. Nenhuma questão da versão traduzida do NCHA II apresentou as opções "muito alterada" ou "completamente alterada", assinaladas em comparação com a versão original.

\section{Discussão}

A etapa de tradução do questionário não apresentou dificuldades na sua realização em razão da metodologia adotada e da estrutura simples e objetiva de formulação das questões e itens do NCHA II. A tradução inicial realizada pelos dois tradutores foi pouco modificada nas etapas subsequentes. A retrotradução, quando comparada ao questionário original, expôs discretas discrepâncias, resultantes de ajustes realizados para atender especificidades de determinados itens. A análise das equivalências semântica e conceitual, equivalente à adaptação transcultural, indicou que o questionário foi de fácil tradução.

A análise das equivalências mostrou que os módulos do NCHA II são apropriados e os atributos utilizados na versão original do questionário são igualmente válidos para a cultura-alvo. A equivalência conceitual indicou que poucos itens necessitaram de ajustes. As questões e os itens puderam ser considerados de maneira semelhante ao formato original, indicando, mais uma vez, que a estrutura de formulação do NCHA II foi bem elaborada. No que se refere à equivalência semântica, a versão traduzida mostrou que $80 \%$ das questões foram avaliadas como "inalterada" e as demais como "pouco alterada" entre as versões original e retrotraduzida do questionário. Nenhum membro do comitê de análise considerou algum item como "pouco alterado", quando da comparação entre as versões dos questionários original, traduzido e retrotraduzido.

O NCHA II traduzido para o português revela ser um questionário promissor para reunir informações relacionadas aos comportamentos de proteção e de risco para a saúde de estudantes universitários brasileiros. A metodologia de tradução adotada proporcionou qualidade e segurança à tradução. A estrutura simples e objetiva de formulação das questões e dos itens da versão original contribuiu para o êxito dessa fase. As etapas iniciais do processo de adaptação transcultural indicaram que os módulos abordados pelo questionário podem ser apropriados à cultura-alvo e que alguns itens necessitaram de pequenos ajustes. Contudo, futuros estudos deverão ser realizados na tentativa de identificar as propriedades psicométricas e os indicadores de validação para que o NCHA II traduzido para o português possa ser efetivamente recomendado para uso com segurança. 
Itens ajustados na versão traduzida para o idioma português do National College Health Assessment (NCHA II).

\begin{tabular}{|c|c|c|}
\hline Item & Versão original & Versão traduzida \\
\hline \multirow[t]{3}{*}{8 e 9} & Esteróides anabólicos & $\begin{array}{l}\text { Acréscimo da expressão "anabolizantes" } \\
\text { entre parênteses como ilustração }\end{array}$ \\
\hline & Inalantes & $\begin{array}{c}\text { Acréscimo da expressão "lança perfume" na relação } \\
\text { dos inalantes ilustrados entre parênteses }\end{array}$ \\
\hline & Êxtase - MDMA & $\begin{array}{c}\text { Acréscimo da expressão "droga do amor" entre } \\
\text { parênteses como ilustração }\end{array}$ \\
\hline 18 & $\begin{array}{l}\text { Marcas comerciais de medicamentos: Prozac, Viagra, } \\
\text { Vicodin, Valium etc. }\end{array}$ & $\begin{array}{l}\text { Foram excluídas todas as marcas comerciais } \\
\text { de medicamentos }\end{array}$ \\
\hline 33 & Relacionamento amoroso & $\begin{array}{c}\text { Acréscimo das expressões "namoro, noivado e casamento" } \\
\text { entre parênteses como ilustração }\end{array}$ \\
\hline 40 & Gripe influenza A H1N1 & $\begin{array}{c}\text { Acréscimo da expressão "gripe suína" entre } \\
\text { parênteses como ilustração }\end{array}$ \\
\hline 41 & Mononucleose & $\begin{array}{c}\text { Acréscimo da expressão "doença do beijo" entre } \\
\text { parênteses como ilustração }\end{array}$ \\
\hline 49 & Medida relatada de altura & $\begin{array}{c}\text { A unidade de medida "polegadas" foi substituída } \\
\text { por "metro/centímetros" }\end{array}$ \\
\hline 50 & Medida relatada de peso corporal & $\begin{array}{c}\text { A unidade de medida "libras" foi substituída } \\
\text { por "quilogramas/gramas" }\end{array}$ \\
\hline 51 & Séries de ensino superior & $\begin{array}{l}\text { Ajustado para as séries de ensino superior de } \\
\text { acordo com o modelo brasileiro }\end{array}$ \\
\hline 52 & Período de estudo & Acréscimo do período noturno \\
\hline 54 & Etnia & $\begin{array}{c}\text { Exclusão das expressões "indígena americana, nativa do Alasca, nativa } \\
\text { do Havaí ou outras ilhas do Pacífico". Foram utilizadas as expressões } \\
\text { "branca, negra, oriental, indígena e outra etnia" }\end{array}$ \\
\hline 58 & Local de residência & A opção "fraternidade" foi excluída \\
\hline 62 & Rendimento acadêmico médio & $\begin{array}{l}\text { Os conceitos "A, B, C, D e E" foram substituídos por } \\
\text { "muito bom, bom, regular, fraco e muito fraco" }\end{array}$ \\
\hline
\end{tabular}

\section{Resumo}

O objetivo do estudo foi realizar as equivalências semântica e conceitual do questionário National College Health Assessment II (NCHA II). Foram realizadas tradução para o português da versão original do NCHA II e retrotradução para o inglês. As versões do questionário foram analisadas por um comitê de juízes. A versão traduzida do NCHA II foi administrada experimentalmente em amostra de 64 estudantes universitários de ambos os sexos. Após discretas modificações apontadas nos processos de tradução, o comitê de juízes conside- rou que a versão para o idioma português do NCHA II apresentou equivalências semântica e conceitual. As etapas iniciais do processo de adaptação transcultural do questionário NCHA II foram satisfatórias. Porém, futuros estudos são necessários para identificar propriedades psicométricas e indicadores de validação previamente à sua efetiva recomendação para uso com segurança.

Conduta de Saúde; Estudantes; Questionários 


\section{Colaboradores}

D. P. Guedes foi responsável pela coordenação do estudo, participou de todas as etapas do trabalho e redigiu a versão final do manuscrito. M. Teixeira participou do trabalho de campo, da análise dos dados e da redação do manuscrito.

\section{Referências}

1. American College Health Association. National College Health Assessment: user's manual. Linthicum: American College Health Association; 2004.

2. American College Health Association. American College Health Association-National College Health Assessment Spring 2008 Reference Group Data Report (abridged): the American College Health Association. J Am Coll Health 2009; 57:477-88.

3. Andrade AG, Duarte PCAV, Oliveira LG. I levantamento nacional sobre o uso de álcool, tabaco e outras drogas entre universitários das 27 capitais brasileiras. Brasília: Secretaria Nacional de Políticas sobre Drogas; 2010.

4. Guillemin F, Bomabardier C, Beaton D. Crosscultural adaptation of health-related quality of life measures: literature review and proposed guidelines. J Clin Epidemiol 1993; 46:1417-32.

Recebido em 03/Jun/2011

Versão final reapresentada em 07/Jul/2011

Aprovado em 15/Dez/2011 